\title{
Vague Implicative LI - Ideals of Lattice Implication Algebras
}

\author{
V. AmarendraBabu ${ }^{1, *}$, T. Anitha ${ }^{2}$ \\ ${ }^{1}$ Department of Mathematics, Acharya Nagarjuna University, India \\ ${ }^{2}$ Department of Mathematics, K.L. University, India
}

Copyright $(\mathcal{C} 2015$ by authors, all rights reserved. Authors agree that this article remains permanently open access under the terms of the Creative Commons Attribution License 4.0 International License

\begin{abstract}
We introduce the concept of vague implicative LI - ideals of lattice implication algebra and discuss some of their properties. We study the relationship between v-implicative filters, vague ILI - ideals and ILI - ideals. Extension property of a vague implicative LI - ideal is built.
\end{abstract}

Keywords Lattice Implication Algebras, ILI - ideals, Vague ILI - ideals, Implicative v- filter

\section{Introduction}

In order to investigate a many valued logical system whose proportional value is given in a lattice, Y. XU $[9,13]$ first established the lattice implication algebra by combining lattice and implication algebra, and explored many useful structures. The ideal theory serves a vital function for the development of lattice implication algebras. Y.XU, Y.B. Jun and E.H. Roh [11] introduced the notion of LI - ideals of lattice implication algebras and examined their properties. And other researchers studied several LI -ideals in lattice implication algebras. In particular Young Lin Liu, Yang Xu, Qin and Liu [7] introduced the notion of ILI - ideals of lattice implication algebras. They gave equivalent conditions of ILI - ideals and provide some equivalent conditions for a LI - ideal to be an ILI - ideal and Implicative filter in lattice implication algebras. Afterwards, Y.XU and Y.B. Jun [12] introduced the notion of fuzzy LI - ideals of lattice implication algebras. Leroy B. Beasley, Gi- Sang Cheon, Y.B. Jun and Seok Zun Song [4] introduced the fuzzy implicative LI - ideals in lattice implication algebras.

The concept of vague set [3] introduced by Gau in 1993. Vague sets as a extension of fuzzy sets, the idea of vague sets is that the membership of every element can be divided into two aspects including supporting and opposing. Since then this idea has been applied to other algebraic structures such as groups, semi groups, rings, vector spaces, topologies and on different algebras like as BM - algebras, MV - algebras and BL - algebras. At first Ya Qin and Yi Liu [6] applied the vague set theory to lattice implication algebra and introduced the notion of $\mathrm{v}$ - filter, and investigated some properties. In [1], we introduced the concept of Vague LI - ideals of lattice implication algebra. Also we study the various properties and equivalent characterizations of vague LI ideals. We investigated the relation between $\mathrm{v}$ - filters, vague $\mathrm{LI}$ - ideals and Li- ideals.

The object of this paper is to make a study of vague implicative LI - ideals and its properties on lattice implication algebras L.

\section{Preliminaries}

In this section we collect some Definitions and important results for further sections.

Definition 2.1: [9] Let $\left(\mathrm{L}, \mathrm{V}, \wedge,{ }^{\prime}, 0, \mathrm{I}\right)$ be a complemented lattice with the universal bounds $0, \mathrm{I}$. $\rightarrow$ is another binary operation of $\mathrm{L}$. ( $\left.\mathrm{L}, \mathrm{V}, \wedge, \rightarrow,{ }^{\prime}, 0, \mathrm{I}\right)$ is called a lattice implication algebra, if the following axioms hold :

$$
\begin{gathered}
\forall \mathrm{x}, \mathrm{y}, \mathrm{z} \in \mathrm{L} \\
\left(\mathrm{I}_{1}\right) \mathrm{x} \rightarrow(\mathrm{y} \rightarrow \mathrm{z})=\mathrm{y} \rightarrow(\mathrm{x} \rightarrow \mathrm{z}) \\
\left(\mathrm{I}_{2}\right) \mathrm{x} \rightarrow \mathrm{x}=\mathrm{I} ; \\
\left(\mathrm{I}_{3}\right) \mathrm{x} \rightarrow \mathrm{y}=\mathrm{y}^{\prime} \rightarrow \mathrm{x}^{\prime} ; \\
\left(\mathrm{I}_{4}\right) \mathrm{x} \rightarrow \mathrm{y}=\mathrm{y} \rightarrow \mathrm{x}=\mathrm{I} \text { implies } \mathrm{x}=\mathrm{y} ; \\
\left(\mathrm{I}_{5}\right)(\mathrm{x} \rightarrow \mathrm{y}) \rightarrow \mathrm{y}=(\mathrm{y} \rightarrow \mathrm{x}) \rightarrow \mathrm{x} ; \\
\left(\mathrm{L}_{1}\right)(\mathrm{x} \vee \mathrm{y}) \rightarrow \mathrm{z}=(\mathrm{x} \rightarrow \mathrm{z}) \wedge(\mathrm{y} \rightarrow \mathrm{z}) \\
\left(\mathrm{L}_{2}\right)(\mathrm{x} \wedge \mathrm{y}) \rightarrow \mathrm{z}=(\mathrm{x} \rightarrow \mathrm{z}) \vee(\mathrm{y} \rightarrow \mathrm{z})
\end{gathered}
$$

Definition 2.2:[9] A lattice implication algebra $(\mathrm{L}, \mathrm{V}, \wedge$, $\left.\rightarrow,{ }^{\prime}, 0, \mathrm{I}\right)$ is said to be a lattice $\mathrm{H}$ implication algebra if it 
satisfy the following axiom:

$$
\mathrm{x} \vee \mathrm{y} \vee((\mathrm{x} \wedge \mathrm{y}) \rightarrow \mathrm{z})=\mathrm{I}, \forall \quad \mathrm{x}, \mathrm{y}, \mathrm{z}
$$

Theorem 2.3:[13] Let L be a lattice implication algebra, then for any $x, y, z \in L$, the following conclusions hold:

(1) If $\mathrm{I} \rightarrow \mathrm{x}=\mathrm{I}$ then $\mathrm{x}=\mathrm{I}$;

(2) $\mathrm{I} \rightarrow \mathrm{x}=\mathrm{x}$ and $\mathrm{x} \rightarrow 0=\mathrm{x}$;

(3) $0 \rightarrow \mathrm{x}=\mathrm{I}$ and $\mathrm{x} \rightarrow \mathrm{I}=\mathrm{I}$;

(4) $\mathrm{x} \leq \mathrm{y}$ if and only if $\mathrm{x} \rightarrow \mathrm{y}$;

(5) $(x \rightarrow z) \rightarrow(x \rightarrow y)=((z \wedge x) \rightarrow y)=(z \rightarrow$ $\mathrm{x}) \rightarrow(\mathrm{z} \rightarrow \mathrm{y})$;

(6) $\mathrm{x} \rightarrow \mathrm{y} \leq(\mathrm{y} \rightarrow \mathrm{z}) \rightarrow(\mathrm{x} \rightarrow \mathrm{z})$;

(7) $((x \rightarrow y) \rightarrow y) \rightarrow y=x \rightarrow y$.

Definition 2.4: [7] Let A be a subset of a lattice implication algebra L. A is said to be an ILI - ideal of L if it satisfies the following conditions:

(1) $0 \in \mathrm{A}$;

(2) $\forall \mathrm{x}, \mathrm{y}, \mathrm{z} \in L,\left(\left((\mathrm{x} \rightarrow \mathrm{y})^{\prime} \rightarrow \mathrm{y}\right)^{\prime} \rightarrow \mathrm{z}\right)^{\prime} \in \mathrm{A}$ and $\mathrm{z} \in \mathrm{A}$ implies $(\mathrm{x} \rightarrow \mathrm{y})^{\prime} \in \mathrm{A}$.

Definition 2.5: [13] Let $F$ be a subset of a lattice implication algebra L. F is said to be a implicative filter of $\mathrm{L}$ if it satisfies the following conditions:

(1) $I \in F$;

(2) $\forall x, y, z$

$\epsilon L,(\mathrm{x} \rightarrow \mathrm{y}) \epsilon \mathrm{F}$ and $(\mathrm{x} \rightarrow$

$(\mathrm{y} \rightarrow \mathrm{z})) \in \mathrm{F}$ implies $(\mathrm{x} \rightarrow \mathrm{z}) \in \mathrm{F}$.

Definition2.6: [3] A vague set A in the universal of discourse $\mathrm{X}$ is characterized by two membership functions given by:

(1) A truth membership function $t_{A}: X \rightarrow[0,1]$ and

(2) A false membership function $\mathrm{f}_{\mathrm{A}}: \mathrm{X} \rightarrow[0,1]$,

Where $t_{A}(x)$ is a lower bound of the grade of membership of $x$ derived from the "evidence for $x$ ", and $f_{A}(x)$ is a lower bound on the negation of $x$ derived from the "evidence against $x "$ and $t_{A}(x)+f_{A}(x) \leq 1$. Thus the grade of membership of $\mathrm{x}$ in the vague set $\mathrm{A}$ is bounded by subinterval $\left[t_{A}(x), 1-f_{A}(x)\right]$ of $[0,1]$. The vague set $A$ is written as

$$
A=\left\{\left\langle x,\left[t_{A}(x), f_{A}(x)\right]\right\rangle / x \in X\right\} .
$$

Where the interval $\left[t_{A}(x), 1-f_{A}(x)\right]$ is called the value of $x$ in the vague set $A$ and denoted by $V_{A}(x)$.

Definition 2.7: [3] Let A be a vague set of a universe $X$ with the truth membership function $\mathrm{tA}$ and the false membership function fA. . For any $\alpha, \beta \in[0,1]$ with $\alpha \leq \beta$, the $(\alpha, \beta)-$ cut or vague cut of a vague set $A$ is a crisp subset $A(\alpha, \beta)$ of the set

$$
\mathrm{X} \text { given by } \mathrm{A}_{(\alpha, \beta)}=\left\{\mathrm{x} \in \mathrm{X} / \mathrm{V}_{\mathrm{A}}(\mathrm{x}) \geq[\alpha, \beta]\right\} .
$$

Definition 2.8: [3] The $\alpha$ - cut, $\mathrm{A}_{\alpha}$ of the vague set $\mathrm{A}$ is the $(\alpha, \alpha)$ - cut of $A$ and hence given by $\mathrm{A}_{\alpha}=\left\{\mathrm{x} \in \mathrm{X} / \mathrm{t}_{\mathrm{A}}(\mathrm{x}) \geq \alpha\right\}$.

Notation: Let $\mathrm{I}[0,1]$ denote the family of all closed subintervals of $[0,1]$. If $\mathrm{I}_{1}=\left[\mathrm{a}_{1}, \mathrm{~b}_{1}\right], \mathrm{I}_{2}=\left[\mathrm{a}_{2}, \mathrm{~b}_{2}\right]$ are two elements of I

$[0,1]$, we call $I_{1} \geq I_{2}$ if $a_{1} \geq a_{2}$ and $b_{1} \geq b_{2}$. We define the term imax to mean the maximum of two interval as imax $\left[\mathrm{I}_{1}, \mathrm{I}_{2}\right]=\left[\max \left\{\mathrm{a}_{1}, \mathrm{a}_{2}\right\}, \max \left\{\mathrm{b}_{1}, \mathrm{~b}_{2}\right\}\right]$.

Similarly, we can define the term imin of any two intervals.

Definition 2.9[1]: Let $A$ be a vague set of a lattice implication algebra L. A is said to be a vague LI - ideal (briefly VLI - ideal) of L if it satisfies the following conditions:

(1) $\forall \mathrm{x} \in L, \mathrm{~V}_{\mathrm{A}}(0) \geq \mathrm{V}_{\mathrm{A}}(\mathrm{x})$,

(2) $\forall \mathrm{x}, \mathrm{y} \in L, \mathrm{~V}_{\mathrm{A}}(\mathrm{x}) \geq \operatorname{imin}\left\{\mathrm{V}_{\mathrm{A}}\left((\mathrm{x} \rightarrow \mathrm{y})^{\prime}\right), \mathrm{V}_{\mathrm{A}}(\mathrm{y})\right\}$.

Definition 2.10[1]: Let $A$ be a vague set of a lattice implication algebra L. A is said to be a vague lattice ideal of $\mathrm{L}$ if it satisfies the following conditions:

(1) If $y \leq x$ then $V_{A}(y) \geq V_{A}(x)$,

(2) $\mathrm{V}_{\mathrm{A}}(\mathrm{x} \vee \mathrm{y}) \geq \operatorname{imin}\left\{\mathrm{V}_{\mathrm{A}}(\mathrm{x}), \mathrm{V}_{\mathrm{A}}(\mathrm{y})\right\}$ for $\mathrm{x}, \mathrm{y} \in \mathrm{L}$.

\section{Vague Implicative LI - ideal}

Definition 3.1: Let A be a vague set of a lattice implication algebra L. A is said to be a vague implicative LI - ideal (briefly VILI - ideal) of L if it satisfies the following conditions:

(1) $\forall \mathrm{x} \in L, \mathrm{~V}_{\mathrm{A}}(0) \geq \mathrm{V}_{\mathrm{A}}(\mathrm{x})$,

(2) $\forall \mathrm{x}, \mathrm{y}, \mathrm{z} \in L, \mathrm{~V}_{\mathrm{A}}\left((\mathrm{x} \rightarrow \mathrm{y})^{\prime}\right) \geq \operatorname{imin}\left\{\mathrm{V}_{\mathrm{A}}\left(\left((\mathrm{x} \rightarrow \mathrm{y})^{\prime} \rightarrow\right.\right.\right.$ $\left.\left.\left.\mathrm{y})^{\prime} \rightarrow \mathrm{z}\right)^{\prime}\right), \mathrm{V}_{\mathrm{A}}(\mathrm{z})\right\}$.

Example 3.2: Let $\mathrm{L}=\{0, \mathrm{a}, \mathrm{b}, \mathrm{c}, \mathrm{d}, \mathrm{I}\}$ be a set with Cayley table as follows:

$\begin{array}{ccccccc}\rightarrow & \text { o } & \text { a } & \text { b } & \text { c } & \text { d } & \text { I } \\ 0 & \text { I } & \text { I } & \text { I } & \text { I } & \text { I } & \text { I } \\ \text { a } & \text { c } & \text { I } & \text { b } & \text { c } & \text { b } & \text { I } \\ \text { b } & \text { d } & \text { a } & \text { I } & \text { b } & \text { a } & \text { I } \\ \text { c } & \text { a } & \text { a } & \text { I } & \text { I } & \text { a } & \text { I } \\ \text { d } & \text { b } & \text { I } & \text { I } & \text { b } & \text { I } & \text { I } \\ \text { I } & \text { a } & \text { a } & \text { b } & \text { c } & \text { d } & \text { I }\end{array}$

Define ',$\vee$ and $\wedge$ operations on $\mathrm{L}$ as follows:

$$
\begin{aligned}
& \mathrm{x}^{\prime}=\mathrm{x} \rightarrow 0, \quad \mathrm{x} \vee \mathrm{y}=(\mathrm{x} \rightarrow \mathrm{y}) \rightarrow \mathrm{y}, \mathrm{x} \wedge \mathrm{y}=\left(\left(\mathrm{x}^{\prime} \rightarrow \mathrm{y}^{\prime}\right)\right. \\
&\left.\rightarrow \mathrm{y}^{\prime}\right)^{\prime} \text { for all } \mathrm{x}, \mathrm{y} \in L .
\end{aligned}
$$

Then $\left(\mathrm{L}, \mathrm{V}, \wedge, \rightarrow,{ }^{\prime}, 0, \mathrm{I}\right)$ is a lattice implication algebra [13]. Define a vague set A of L by 
$\mathrm{A}=$

$\{\langle 0,[0.7,0.2]\rangle$,

$\langle a,[0.7,0.2]\rangle,\langle b,[0.5,0.3]\rangle,\langle c,[0.5,0.3]\rangle,\langle d,[0.7,0.2]\rangle,\langle I,[0.5,0.3]\rangle\}$.

One can easily verify that A is a VILI - ideal of L.

We give the relation between VILI - ideals and VLIideals of lattice implication algebras:

Theorem 3.3: Any VILI - ideal of a lattice implication algebra $\mathrm{L}$ is a VLI - ideal of L.

Proof: Let A be a VILI - ideal of a lattice implication algebra L. Then obviously, $\mathrm{V}_{\mathrm{A}}(0) \geq \mathrm{V}_{\mathrm{A}}(\mathrm{x}) \forall \mathrm{x} \in L$.

Let $\mathrm{x}, \mathrm{y}, \mathrm{z} \in L$, then we have $\mathrm{V}_{\mathrm{A}}\left((\mathrm{x} \rightarrow \mathrm{y})^{\prime}\right) \geq \operatorname{imin}\left\{\mathrm{V}_{\mathrm{A}}\right.$ $\left.\left.\left(\left((\mathrm{x} \rightarrow \mathrm{y})^{\prime} \rightarrow \mathrm{y}\right)^{\prime} \rightarrow \mathrm{z}\right)^{\prime}\right), \mathrm{V}_{\mathrm{A}}(\mathrm{z})\right\}$

Taking $\mathrm{y}=0$ in the above equation, we obtain

$\mathrm{V}_{\mathrm{A}}\left((\mathrm{x} \rightarrow 0)^{\prime}\right) \geq \operatorname{imin}\left\{\mathrm{V}_{\mathrm{A}}\left(\left((\mathrm{x} \rightarrow 0)^{\prime} \rightarrow 0\right)^{\prime} \rightarrow \mathrm{z}\right)^{\prime}\right)$, $\left.\mathrm{V}_{\mathrm{A}}(\mathrm{z})\right\}$

$\left.\mathrm{V}_{\mathrm{A}}\left(\left(\mathrm{x}^{\prime}\right)^{\prime}\right)=\operatorname{imin}\left\{\mathrm{V}_{\mathrm{A}}\left(\left(\left(\mathrm{x}^{\prime}\right)^{\prime} \rightarrow 0\right)^{\prime} \rightarrow \mathrm{z}\right)^{\prime}\right), \mathrm{V}_{\mathrm{A}}(\mathrm{z})\right\}$

$\left.\mathrm{V}_{\mathrm{A}}(\mathrm{x})=\operatorname{imin}\left\{\mathrm{V}_{\mathrm{A}}\left((\mathrm{x} \rightarrow 0)^{\prime} \rightarrow \mathrm{z}\right)^{\prime}\right), \mathrm{V}_{\mathrm{A}}(\mathrm{z})\right\}$

$=\operatorname{imin}\left\{\mathrm{V}_{\mathrm{A}}\left((\mathrm{x} \rightarrow \mathrm{z})^{\prime}\right), \mathrm{V}_{\mathrm{A}}(\mathrm{z})\right\}$.

Hence $\mathrm{A}$ is a VLI - ideal of L.

The converse of theorem 3.3 may not be true as seen in the following example:

Example 3.4: The vague set

$\mathrm{B}=\{\langle 0,[0.7,0.2]\rangle$

$\langle a,[0.5,0.3]\rangle,\langle b,[0.5,0.3]\rangle,\langle c,[0.7,0.2]\rangle,\langle d,[0.5,0.3]\rangle,\langle I,[0.5,0.3]\rangle\}$

of L ( in example 3.2) is a VLI - ideal of L. But it is not a VILI - ideal of L because

$\left.\mathrm{V}_{\mathrm{A}}\left((\mathrm{a} \rightarrow \mathrm{b})^{\prime}\right) \geq \operatorname{imin}\left\{\mathrm{V}_{\mathrm{A}}\left(\left((\mathrm{a} \rightarrow \mathrm{b})^{\prime} \rightarrow \mathrm{b}\right)^{\prime} \rightarrow 0\right)^{\prime}\right), \mathrm{V}_{\mathrm{A}}(0)\right\}$.

Theorem3.5: In a lattice $\mathrm{H}$ implication algebra L, every VLI - ideal is a VILI - ideal.

Proof: Let A be any VLI - ideal of a lattice $\mathrm{H}$ implication algebra L.

Then obviously, $\mathrm{V}_{\mathrm{A}}(0) \geq \mathrm{V}_{\mathrm{A}}(\mathrm{x})$ for all $\mathrm{x} \in L$.

We have, $\mathrm{V}_{\mathrm{A}}\left((\mathrm{x} \rightarrow \mathrm{y})^{\prime}\right)=\mathrm{V}_{\mathrm{A}}\left(\left(\mathrm{y}^{\prime} \rightarrow \mathrm{x}^{\prime}\right)^{\prime}\right)$

$$
=\mathrm{V}_{\mathrm{A}}\left(\left(\mathrm{y}^{\prime} \rightarrow\left(\mathrm{y}^{\prime} \rightarrow \mathrm{x}^{\prime}\right)\right)^{\prime}\right) \quad(\text { since } \mathrm{L} \text { is lattice } \mathrm{H}
$$
implication algebra)

$$
\begin{aligned}
& =\mathrm{V}_{\mathrm{A}}\left(\left(\mathrm{y}^{\prime} \rightarrow(\mathrm{x} \rightarrow \mathrm{y})\right)^{\prime}\right) \\
= & \mathrm{V}_{\mathrm{A}}\left(\left((\mathrm{x} \rightarrow \mathrm{y})^{\prime} \rightarrow \mathrm{y}\right)^{\prime}\right)
\end{aligned}
$$

$\left.\geq \operatorname{imin}\left\{\mathrm{V}_{\mathrm{A}}\left(\left((\mathrm{x} \rightarrow \mathrm{y})^{\prime} \rightarrow \mathrm{y}\right)^{\prime} \rightarrow \mathrm{z}\right)^{\prime}\right), \mathrm{V}_{\mathrm{A}}(\mathrm{z})\right\}$. (by $\left.2.9(2)\right)$

Hence $\mathrm{A}$ is a VILI - ideal of L.

Corolloary3.6: Every VILI- ideal A of a lattice implication algebra $\mathrm{L}$ is order reversing.

Corolloary3.7: Every VILI - ideal of a lattice implication algebra $\mathrm{L}$ is a vague lattice ideal of $\mathrm{L}$ Converse need not to be true.
Remark 3.8: In a lattice $\mathrm{H}$ implication algebra $\mathrm{L}$, every vague lattice ideal is a VILI -ideal.

Example 3.9: Let $L=\{0, a, b, I\}$ be a set with Cayley table as follows:

$\begin{array}{ccccc}\rightarrow & 0 & \mathrm{a} & \mathrm{b} & \mathrm{I} \\ 0 & \mathrm{I} & \mathrm{I} & \mathrm{I} & \mathrm{I} \\ \mathrm{a} & \mathrm{b} & \mathrm{I} & \mathrm{b} & \mathrm{I} \\ \mathrm{b} & \mathrm{a} & \mathrm{a} & \mathrm{I} & \mathrm{I} \\ \mathrm{I} & 0 & \mathrm{a} & \mathrm{b} & \mathrm{I}\end{array}$

Define ', $\vee$ and $\wedge$-operations on $\mathrm{L}$ as follows: $\mathrm{x}^{\prime}=\mathrm{x} \rightarrow 0, \mathrm{x} \vee \mathrm{y}=(\mathrm{x} \rightarrow \mathrm{y}) \rightarrow \mathrm{y}, \mathrm{x} \wedge \mathrm{y}=\left(\left(\mathrm{x}^{\prime} \rightarrow \mathrm{y}^{\prime}\right) \rightarrow \mathrm{y}^{\prime}\right)^{\prime}$ for all $\mathrm{x}, \mathrm{y} \in L$.

Then $\left(\mathrm{L}, \mathrm{V}, \wedge, \rightarrow,{ }^{\prime}, 0, \mathrm{I}\right)$ is a lattice $\mathrm{H}$ implication algebra [13]. Let $\mathrm{C}$ be a vague set in $\mathrm{L}$ defined by

$\mathrm{C}=\{\langle 0,[0.7,0.2]\rangle,\langle a,[0.5,0.3]\rangle,\langle b,[0.5,0.3]\rangle$,

$\langle I,[0.5,0.3]\rangle\}$. L.

Clearly, $\mathrm{C}$ is both VILI - ideal and vague lattice ideal of

Theorem 3.10: Let A be a vague set of a lattice implication algebra L. Then A is a VILI - ideal of L if and only if

$\mathrm{A}_{(\alpha, \beta)}$ is an ILI - ideal of $\mathrm{L}$ when $\mathrm{A}_{(\alpha, \beta)} \neq \varnothing, \alpha, \beta \in[0,1]$.

Proof: Assume that A is a VILI - ideal of L and $\alpha, \beta \in[0,1]$ such that $\mathrm{A}_{(\alpha, \beta)} \neq \varnothing$.

Then there exist $x \in A_{(\alpha, \beta)}$, and hence $V_{A}(0) \geq V_{A}(x) \geq$ $[\alpha, \beta]$. That is $0 \in \mathrm{A}_{(\alpha, \beta)}$.

Let $\mathrm{x}, \mathrm{y}, z \in L$, if $\left(\left((\mathrm{x} \rightarrow \mathrm{y})^{\prime} \rightarrow \mathrm{y}\right)^{\prime} \rightarrow \mathrm{z}\right)^{\prime} \in \mathrm{A}_{(\alpha, \beta)}$ and $\mathrm{z} \epsilon$ $\mathrm{A}_{(\alpha, \beta)}$ then

$$
\begin{aligned}
& \mathrm{V}_{\mathrm{A}}\left(\left(\left((\mathrm{x} \rightarrow \mathrm{y})^{\prime} \rightarrow \mathrm{y}\right)^{\prime} \rightarrow \mathrm{z}\right)^{\prime}\right) \geq[\alpha, \beta], \mathrm{V}_{\mathrm{A}}(\mathrm{z}) \geq[\alpha, \beta] . \text { It } \\
& \text { follows that } \\
& \begin{aligned}
\mathrm{V}_{\mathrm{A}}\left((\mathrm{x} \rightarrow \mathrm{y})^{\prime}\right) \geq \operatorname{imin}\left\{\mathrm{V}_{\mathrm{A}}\left(\left((\mathrm{x} \rightarrow \mathrm{y})^{\prime} \rightarrow \mathrm{y}\right)^{\prime} \rightarrow \mathrm{z}\right)^{\prime}\right), \\
\left.\mathrm{V}_{\mathrm{A}}(\mathrm{z})\right\} \geq[\alpha, \beta],
\end{aligned}
\end{aligned}
$$

That is $(\mathrm{x} \rightarrow \mathrm{y})^{\prime} \in \mathrm{A}_{(\alpha, \beta)}$. So, $\mathrm{A}_{(\alpha, \beta)}$ is an ILI ideal of $\mathrm{L}$.

Conversely, Suppose that for any $\alpha, \beta \in[0,1], \mathrm{A}_{(\alpha, \beta)}$ $\neq \varnothing$ is an ILI - ideal of L. For any $\mathrm{x} \in L, \mathrm{x} \in \mathrm{A}_{\mathrm{A}(\mathrm{x})}$ and hence $A_{A(x)}$ is an ILI ideal of L. By $0 \in A_{A(x)}$ it follows that $\mathrm{V}_{\mathrm{A}}(0) \geq \mathrm{V}_{\mathrm{A}}(\mathrm{x})$. For any $\mathrm{x}, \mathrm{y}, z \in L$, let

$$
[\alpha, \beta]=\operatorname{imin}\left\{\mathrm{V}_{\mathrm{A}}\left(\left(\left((\mathrm{x} \rightarrow \mathrm{y})^{\prime} \rightarrow \mathrm{y}\right)^{\prime} \rightarrow \mathrm{z}\right)^{\prime}\right), \mathrm{V}_{\mathrm{A}}(\mathrm{z})\right\},
$$

It follows that $\mathrm{A}_{(\alpha, \beta)} \neq \varnothing$ and hence $\mathrm{A}_{(\alpha, \beta)}$ is an ILI ideal of L. Since $\left.\left((x \rightarrow y)^{\prime} \rightarrow y\right)^{\prime} \rightarrow z\right)^{\prime} \in A_{(\alpha, \beta),} z \in A_{(\alpha, \beta)}$ this implies $(\mathrm{x} \rightarrow \mathrm{y})^{\prime} \in \mathrm{A}_{(\alpha, \beta)}$. That is

$$
\begin{gathered}
\mathrm{V}_{\mathrm{A}}\left((\mathrm{x} \rightarrow \mathrm{y})^{\prime}\right) \geq[\alpha, \beta]= \\
\left.\left.\mathrm{z})^{\prime}\right), \mathrm{V}_{\mathrm{A}}(\mathrm{z})\right\} .
\end{gathered}
$$

So, $\mathrm{A}$ is a VI LI - ideal of L. 
Corollary 3.11: Let $\mathrm{A}$ be a vague set of a lattice implication algebra $\mathrm{L}$. Then $\mathrm{A}$ is a VILI - ideal of L if and only if $\mathrm{A}_{\alpha}$ is an ILI - ideal when $\mathrm{A}_{\alpha} \neq \emptyset, \alpha \in[0,1]$.

Theorem3.12: (Extension property for VILI - ideals) Let A and $B$ be VLI- ideals of lattice implication algebra $L$ such that $\mathrm{A} \subseteq \mathrm{B}$, that is $\mathrm{V}_{\mathrm{A}}(\mathrm{x}) \leq \mathrm{V}_{\mathrm{B}}(\mathrm{x}), \forall \mathrm{x} \in L$. If $\mathrm{A}$ is a VILIideal of $\mathrm{L}$, then so is $\mathrm{B}$.

Proof: Let A and B are VLI - ideals of lattice implication algebra $\mathrm{L}$ such that $\mathrm{A} \subseteq \mathrm{B}$.

Since $\mathrm{A} \subseteq \mathrm{B}$, that is $\mathrm{V}_{\mathrm{A}}(\mathrm{x}) \leq \mathrm{VB}(\mathrm{x}) \forall \mathrm{x} \in L$, implies that $\mathrm{A} \alpha \subseteq \mathrm{B} \alpha$ for every $\alpha \in[0,1]$.

If $\mathrm{A}$ is a VILI- ideal of $\mathrm{L}$ then by corollary $3.11, \mathrm{~A} \alpha$ $\neq \varnothing$ is an ILI - ideal for $\alpha \in[0,1]$. Using theorem 3.9[7], B $\alpha \neq \emptyset$ is an ILI - ideal $\alpha \in[0,1]$. It follows from corollary 3.11 that B is a VILI - ideal of lattice implication algebra L.

Theorem 3.13: Let I be an ILI - ideal of a lattice implication algebra $\mathrm{L}$. The vague set A defined by

$\mathrm{V}_{\mathrm{A}}(\mathrm{x})=[\alpha, \alpha]$ if $\mathrm{x} \in \mathrm{I}$ and $\mathrm{V}_{\mathrm{A}}(\mathrm{x})=[0,0]$ if $\mathrm{x} \notin \mathrm{I}$ is a VILI - ideal of L, where $\alpha \in[0,1]$.

Proof: Let $\mathrm{A}$ be a vague set of $\mathrm{L}$, defined by $\mathrm{V}_{\mathrm{A}}(\mathrm{x})=[\alpha, \alpha]$ if $x \in I$ and $V_{A}(x)=[0,0]$ if $x \notin I$, where $\alpha \in[0,1]$. Since 0 $\in \mathrm{I}$, we have $\mathrm{V}_{\mathrm{A}}(0)=[\alpha, \alpha] \geq \mathrm{V}_{\mathrm{A}}(\mathrm{x}) \forall \mathrm{x} \in L$. Let $\mathrm{x}, \mathrm{y} \in L$. If $(\mathrm{x} \rightarrow \mathrm{y})^{\prime} \in \mathrm{I}$ then

$$
\begin{gathered}
\mathrm{V}_{\mathrm{A}}\left((\mathrm{x} \rightarrow \mathrm{y})^{\prime}\right)=[\alpha, \alpha] \geq \operatorname{imin}\left\{\mathrm { V } _ { \mathrm { A } } \left(\left((\mathrm{x} \rightarrow \mathrm{y})^{\prime} \rightarrow \mathrm{y}\right)^{\prime} \rightarrow\right.\right. \\
\left.\left.\mathrm{z})^{\prime}\right), \mathrm{V}_{\mathrm{A}}(\mathrm{z})\right\} .
\end{gathered}
$$

Assume that $(\mathrm{x} \rightarrow \mathrm{y})^{\prime} \notin \mathrm{I}$ then either $\left(\left((\mathrm{x} \rightarrow \mathrm{y})^{\prime} \rightarrow\right.\right.$ $\left.\mathrm{y})^{\prime} \rightarrow \mathrm{z}\right)^{\prime} \notin \mathrm{I}$ or $\mathrm{z} \notin \mathrm{I}$. It follows that

$\mathrm{V}_{\mathrm{A}}\left((\mathrm{x} \rightarrow \mathrm{y})^{\prime}\right)=[0,0]=\operatorname{imin}\left\{\mathrm{V}_{\mathrm{A}}\left(\left((\mathrm{x} \rightarrow \mathrm{y})^{\prime} \rightarrow \mathrm{y}\right)^{\prime} \rightarrow\right.\right.$

$$
\left.\left.\mathrm{z})^{\prime}\right), \mathrm{V}_{\mathrm{A}}(\mathrm{z})\right\} \text {. }
$$

So $\mathrm{A}$ is a VILI - ideal of $\mathrm{L}$.

Theorem3.14: Let A be a VILI - ideal of a lattice implication algebra $\mathrm{L}$.

Then $\mathrm{I}=\left\{\mathrm{x} \in \mathrm{L} / \mathrm{V}_{\mathrm{A}}(\mathrm{x})=\mathrm{V}_{\mathrm{A}}(0)\right\}$ is an ILI - ideal of $\mathrm{L}$.

Proof: Let $\mathrm{I}=\left\{\mathrm{x} \in \mathrm{L} / \mathrm{V}_{\mathrm{A}}(\mathrm{x})=\mathrm{V}_{\mathrm{A}}(0)\right\}$, obviously $0 \in \mathrm{I}$. Let $\mathrm{x}, \mathrm{y}, \mathrm{z} \in \mathrm{L}$ such that $\left(\left((\mathrm{x} \rightarrow \mathrm{y})^{\prime} \rightarrow \mathrm{y}\right)^{\prime} \rightarrow \mathrm{z}\right)^{\prime}, \mathrm{z} \in \mathrm{I}$.

Then $\left.\mathrm{V}_{\mathrm{A}}\left(\left((\mathrm{x} \rightarrow \mathrm{y})^{\prime} \rightarrow \mathrm{y}\right)^{\prime} \rightarrow \mathrm{z}\right)^{\prime}\right)=\mathrm{V}_{\mathrm{A}}(\mathrm{z})=\mathrm{V}_{\mathrm{A}}(0)$ and so $\left.\mathrm{V}_{\mathrm{A}}\left((\mathrm{x} \rightarrow \mathrm{y})^{\prime}\right) \geq \operatorname{imin}\left\{\mathrm{V}_{\mathrm{A}}\left(\left((\mathrm{x} \rightarrow \mathrm{y})^{\prime} \rightarrow \mathrm{y}\right)^{\prime} \rightarrow \mathrm{z}\right)^{\prime}\right), \mathrm{V}_{\mathrm{A}}(\mathrm{z})\right\}$ $=\mathrm{VA}(0)$.

Since $\mathrm{V}_{\mathrm{A}}(0) \geq \mathrm{V}_{\mathrm{A}}\left((\mathrm{x} \rightarrow \mathrm{y})^{\prime}\right)$ for all $\mathrm{x}, \mathrm{y} \in \mathrm{I}$, it follows that $\mathrm{V}_{\mathrm{A}}\left((\mathrm{x} \rightarrow \mathrm{y})^{\prime}\right)=\mathrm{V}_{\mathrm{A}}(0)$, and there by $(\mathrm{x} \rightarrow \mathrm{y})^{\prime} \in \mathrm{I}$.

Therefore I is an ILI - ideal of L.

Example3.15: The vague set

$\mathrm{A}=\{\langle 0,[0.7,0.2]\rangle$,

$\langle a,[0.7,0.2]\rangle,\langle b,[0.5,0.3]\rangle,\langle c,[0.5,0.3]\rangle,\langle d,[0.7,0.2]\rangle,\langle I,[0.5$,

$0.3]\rangle\}$ of $L$ ( in example 3.2) is a VILI - ideal of L. Define $I=\{x \in$

$\mathrm{L} / \mathrm{VA}(\mathrm{x})=\mathrm{VA}(0)\}$, then $\mathrm{I}=\{0, \mathrm{a}, \mathrm{d}\}$.
Clearly I is an ILI - ideal of L.

Definition 3.16: Let $F$ be a vague set of a lattice implication algebra L. F is said to be a Implicative $\mathrm{v}$ - filter of $\mathrm{L}$ if it satisfies the following conditions:

(1) $\forall \mathrm{x} \in L, \mathrm{~V}_{\mathrm{F}}(\mathrm{I}) \geq \mathrm{V}_{\mathrm{F}}(\mathrm{x})$,

(2) $\forall x, y, z \in L, V_{F}(x \rightarrow z) \geq \operatorname{imin}\left\{V_{F}(x \rightarrow y), V_{F}\right.$

$$
(\mathrm{x} \rightarrow(\mathrm{y} \rightarrow \mathrm{z}))\}
$$

Example 3.17: Clearly the vague set

$\mathrm{D}=\{\langle 0,[0.5,0.3]\rangle$,

$\langle a,[0.5,0.3]\rangle,\langle b,[0.7,0.2]\rangle,\langle c,[0.7,0.2]\rangle,\langle d,[0.5,0.3]\rangle,\langle I,[0.7,0.2]\rangle\}$ of $\mathrm{L}$

( in example 3.2) is an implicative $\mathrm{v}$ - filter of $\mathrm{L}$.

Theorem 3.18: Let $F$ be a vague set of a lattice implication algebra $\mathrm{L}$. Then $\mathrm{F}$ is an implicative $\mathrm{v}$ - filter of $\mathrm{L}$ if and only if $\mathrm{F}_{(\alpha, \beta)}$ is an implicative filter of $\mathrm{L}$ when $\mathrm{F}_{(\alpha, \beta)} \neq \varnothing, \alpha, \beta \epsilon$ $[0,1]$.

Proof: Assume that $\mathrm{F}$ is an implicative $\mathrm{v}$ - filter of $\mathrm{L}$ and $\alpha, \beta$ $\epsilon[0,1]$ such that $\mathrm{F}_{(\alpha, \beta)} \neq \varnothing$.

Then there exist $\mathrm{x} \in \mathrm{L}$ such that $\mathrm{x} \in \mathrm{A}_{(\alpha, \beta)}$, and hence $\mathrm{V}_{\mathrm{A}}(\mathrm{I}) \geq[\alpha, \beta]$. That is $\mathrm{I} \in \mathrm{F}_{(\alpha, \beta)}$.

Let $\mathrm{x}, \mathrm{y}, z \in L$, if $\mathrm{x} \rightarrow \mathrm{y} \in \mathrm{F}_{(\alpha, \beta)}$ and $\mathrm{x} \rightarrow(\mathrm{y} \rightarrow \mathrm{z}) \in \mathrm{F}_{(\alpha, \beta)}$ then $\mathrm{V}_{\mathrm{F}}(\mathrm{x} \rightarrow \mathrm{y}) \geq[\alpha, \beta], \quad \mathrm{V}_{\mathrm{F}}(\mathrm{x} \rightarrow(\mathrm{y} \rightarrow \mathrm{z})) \geq[\alpha, \beta]$.

It follows that $\mathrm{V}_{\mathrm{F}}(\mathrm{x} \rightarrow \mathrm{z}) \geq \operatorname{imin}\left\{\mathrm{V}_{\mathrm{F}}(\mathrm{x} \rightarrow(\mathrm{y} \rightarrow \mathrm{z}))\right.$, $\left.\mathrm{V}_{\mathrm{F}}(\mathrm{x} \rightarrow \mathrm{y})\right\} \geq[\alpha, \beta]$

That is $(x \rightarrow z) \in F_{(\alpha, \beta) .}$. So, $F_{(\alpha, \beta)}$ is an implicative filter of L.

Conversely, Suppose that $\mathrm{F}_{(\alpha, \beta)} \neq \varnothing$ is an implicative filter of $\mathrm{L}, \forall \alpha, \beta \in[0,1]$.

For any $\mathrm{x} \in L, \mathrm{x} \in \mathrm{F}_{\mathrm{F}(\mathrm{x})}$, and hence $\mathrm{F}_{\mathrm{F}(\mathrm{x})}$ is an implicative filter of $\mathrm{L}$. By $\mathrm{I} \in \mathrm{F}_{\mathrm{F}(\mathrm{x})}$, it follows that $\mathrm{V}_{\mathrm{F}}(\mathrm{I}) \geq$ $\mathrm{V}_{\mathrm{F}}(\mathrm{x})$.

Let $\mathrm{x}, \mathrm{y}, z \in L$, let $[\alpha, \beta]=\operatorname{imin}\left\{\mathrm{V}_{\mathrm{F}}(\mathrm{x} \rightarrow(\mathrm{y} \rightarrow \mathrm{z}))\right.$, $\left.\mathrm{V}_{\mathrm{F}}(\mathrm{x} \rightarrow \mathrm{y})\right\}$,

It follows that $\mathrm{F}_{(\alpha, \beta)} \neq \varnothing$ and hence $\mathrm{F}_{(\alpha, \beta)}$ is an implicative filter of $\mathrm{L}$.

Since $x \rightarrow(y \rightarrow z) \in F_{(\alpha, \beta)}, x \rightarrow y \in F_{(\alpha, \beta)}$ This implies that $(\mathrm{x} \rightarrow \mathrm{z}) \in \mathrm{F}_{(\alpha, \beta)}$.

That is $\mathrm{V}_{\mathrm{F}}(\mathrm{x} \rightarrow \mathrm{z}) \geq[\alpha, \beta]=\operatorname{imin}\left\{\mathrm{V}_{\mathrm{F}}(\mathrm{x} \rightarrow(\mathrm{y} \rightarrow \mathrm{z}))\right.$, $\mathrm{V}_{\mathrm{F}}(\mathrm{x} \rightarrow \mathrm{y})$ \}.

So, $\mathrm{F}$ is an implicative $\mathrm{v}$ - filter of $\mathrm{L}$.

Corollary 3.19: Let $F$ be a vague set of a lattice implication algebra $\mathrm{L}$. Then $\mathrm{F}$ is a implicative $\mathrm{v}$ - filter of $\mathrm{L}$ if and only if $\mathrm{F}_{\alpha}$ is an implicative filter of $\mathrm{L}$, when $\mathrm{F}_{\alpha} \neq \emptyset, \alpha \in[0,1]$. 
Theorem3.20: Let A be a vague set of a lattice implication algebra $\mathrm{L}$. Then $\mathrm{A}$ is an implicative $\mathrm{v}$ - filter of $\mathrm{L}$ if and only if $\mathrm{A}^{\prime}$ is a VILI - ideal of $\mathrm{L}$.

Proof: Let A be an implicative v- filter of L .By corollary $3.19, \mathrm{~A}_{\alpha}$ is an implicative filter of $\mathrm{L}$.

By the theorem 3.7 in [7], $(\mathrm{A} \alpha)^{\prime}$ is an ILI- ideal of L.

It is obvious that if $\mathrm{A}$ is a vague set of $\mathrm{L}$ then $\left(\mathrm{A}^{\prime}\right) \alpha=(\mathrm{A}$

$\alpha)^{\prime}, \forall \alpha \in[0,1]$.

Then $\left(\mathrm{A}^{\prime}\right) \alpha$ is an ILI - ideal of L.

By the corollary 3.10, we have $\mathrm{A}^{\prime}$ is a VILI - ideal of L.

Hence the theorem.

\section{REFERENCES}

[1] Anitha.T, Amarendra Babu.V, Vague LI - ideals on lattice implication algebra, Journal of Emerging Trends in Computing and Information Sciences,5 (10)(2014), 788 793

[2] Biswas R, Vague Groups, Int. J. Comput. Cognition, 4 (2) (2006), $20-23$.

[3] Gau W. L., Buehrer D. J., Vague sets, IEEE Transactions on Systems, Man and Cybernetics, 23(20)(1993), 610 - 614.

[4] Leroy B. Beasley, Gi- Sang Cheon,Y.B.Jun and Seok Zun Song, Fuzzy implicative LI - ideals in lattice implication
Algebras, Scientiae Mathematicae Japonicae online, vol. $9,(2003), 37-48$.

[5] L. A Zadeh, Fuzzy sets Information and Control 8 (1965), $338-353$.

[6] Ya Qin and Yi Liu, V- filter on lattice implication algebras, Journal of Emerging Trends in Computing and Information Sciences, 3(9)(2012), 1298 - 1301.

[7] Y.L.Liu, S.Y.Liu, Y.Xu and K.Y.Qin, ILI - ideals and prime LI - ideals in lattice implication algebras, information Sciences 155 (2003), 157 - 175.

[8] Y.B. Jun and C.H. Park, Ideals of PSEUDO MV - algebras based on vague set theory, Iranian journal of Fuzzy systems 6(2)(2009),31-45.

[9] Y. Xu, Lattice implication algebras, J. Southwest Jiaotong University 28(1) (1993), $20-27$.

[10] Y. Xu, Homomorphism's in lattice implication algebras, Proc. of 5th Many - valued Logical Congress of China (1992), 206-211

[11] Y.Xu, Y.B. Jun and E.H. Roh, LI - ideals in lattice implication algebras, Bull. Korean Math. Soc. 35(1) (1998), $13-23$

[12] Y.Xu and Y.B. Jun, Fuzzy LI - ideals in lattice implication algebras, J. Fuzzy Math. 7(4) (1999), 997 -1003.

[13] Y. Xu, D. Ruan, K.Y. Qin, Lattice - Valued Logic - an alternative approach to treat fuzziness and incomparability, Springer, 2003. 